\title{
O ESPAÇO NO TEATRO PÓS-DRAMÁTICO: VESTÍGIOS NO TRABALHO DESVIO DO ERRO GRUPO DE FLORIANÓPOLIS. ${ }^{1}$
}

Stephan Arnulf Baumgärtel

Elisza Peressoni Ribeiro

RESUMO: O teatro pós-dramático, classificado por Hans-Thies Lehmann, tem na escolha e na relação com o espaço cênico um de seus elementos mais importantes. Pensar de que forma o espaço no teatro pós-dramático é utilizado, examinado suas motivações e consequiências é o objetivo do presente artigo. Como exemplo de algumas características utilizamos o espetáculo Desvio, do Erro Grupo de Florianópolis

PALAVRAS-CHAVE: Dramaturgia; Teorias da Recepção; Teatro pós-dramático; Análise de espetáculo.

No século XVIII o drama enquanto gênero teatral torna-se hegemônico e suas regras e cânones são respeitados e valorizados. A partir da virada do século XIX para o século XX, no entanto, sua estrutura entra em crise e o teatro passa a se confrontar cada vez mais com seu limite tênue e delicado com a vida. Essa mudança, no entanto, não foi rápida nem imediata e surgiu mediante várias causas e fatores:

Uma série de tendências históricas contribuíram para que esta estética do teatro dramático mudasse: a abertura do teatro em direção a outras formas de arte, exigida já por volta de 1900; a concepção radicalmente nova do corpo no teatro; a crescente importância das mídias tecnológicas, e a transformação geral da vida social em direção ao espetáculo, ao festival, ao evento. (Primavesi, 2004, p. 01)

\footnotetext{
${ }^{1}$ O Tetro pós-dramático na Alemanha: contextos estéticos e culturais, Centro de Artes - CEART; Prof. Doutor Stephan Arnulf Baümgartel, Departamento de Artes Cênicas - DAC; Elisza Peressoni Ribeiro.
} 
Muitas manifestações estéticas surgem neste contexto, não apenas na área teatral, e algumas são semelhantes entre si e outras muito distintas. Mas neste sentido, é com o teatro pós-dramático, de acordo com o estudo fundamental de Hans-Thies Lehmann publicado originalmente em alemão no ano de 1999, que percebemos a maior hibridização entre vida e ficção. A mescla das diferentes linguagens artísticas entre si e também a mescla com as novas mídias comunicacionais são fatores indispensáveis para que possa ser possível entender o surgimento do teatro pós-dramático. Da mesma maneira as novas formas de entender e configurar o corpo, sua nova utilização e abordagem fora e dentro de cena ajudam a analisar e classificar esse gênero. Neste artigo, no entanto, fixamos nossa atenção ao espaço cênico, mas é preciso ressaltar que não ignoramos a necessidade de entendimento destas novas características e suas influências sobre a escolha e a utilização do espaço.

Para questionar a vida pragmática e o contexto social, o teatro pós-dramático utiliza-se de signos híbridos para expor a realidade e ao mesmo tempo pô-la em dúvida. A criação destes signos híbridos é feita de vários modos, busca influência em outras manifestações artísticas, como as artes plásticas e as performances, e se mantém ou é perdida de acordo com a finalidade estética que se deseja atingir. O espaço é apenas um dos elementos que contribuem para essa nova percepção, mas suas possibilidades são influentes, importantes e podem ser muitas:

Onde o teatro é apresentado, em que contexto espacial e institucional, e qual papel ou função ele aloca ao espectador em cada caso, é tão importante quanto as estratégias artísticas, os textos com os quais trabalha ou os temas que aborda no contexto de processos sociais transformativos. Muito além da função estética de serem espaços cênicos, os lugares de apresentação e as instituições se revelam como fatores que determinam as possibilidades de um trabalho de encenação' (Ibiden)

O espaço no teatro pós-dramático é escolhido e utilizado com a intenção de criar possibilidades de percepções não comuns, extracotidianas "sobretudo por possibilitar uma nova consciência da situação que por teatro, desde sempre, significa enquanto prática cultural: o acontecimento de um encontro entre pessoas que atuam e 
espectadores" (Idem, p. 02). Ou seja, o objetivo da utilização de espaços não convencionais não está apenas em retirar o espetáculo teatral de sua caixa cênica tradicional e romper com o palco frontal, mas principalmente em questionar o próprio teatro enquanto forma e local de encontro e percepção, assim como sua importância , influência e validade social. Sair do prédio teatral tradicional significa não apenas quebrar a ilusão da quarta parede ou a distância entre o palco e o público, mas também inserir lugares cotidianos e reais na manifestação teatral, e assim mesclar diretamente a vida e a arte, caminhando no limite tênue que aí há e aproveitando este limite para questionar. Obviamente essa mudança de e na utilização do espaço para a manifestação teatral não tem origem nem é exclusividade das manifestações pós-dramáticas, mas sua especificidade reside no fato de que:

no teatro pós-dramático o espaço se torna uma parte do mundo, decerto enfatizada, mas pensada como algo que permanece no continuum do real: um recorte delimitado no tempo e no espaço, mas ao mesmo tempo continuação e por isso fragmento da realidade e da vida. (Lehmann, 2007, p. 268)

No espetáculo Desvio $^{2}$, que utilizamos neste artigo como espetáculo-exemplo, essa abordagem do espaço pode ser claramente identificada na maneira como a peça se desenvolve e na maneira como o trajeto é escolhido. O enredo do espetáculo consiste em um assassinato que está prestes a ocorrer, porém que não ocorre e muitos acontecimentos remetem claramente à vida urbana das grandes cidades. Caminhando pela cidade as personagens conduzem os espectadores por ruas pelas quais eles costumam passar todos os dias, ruas movimentadas e ruas principais, e nas quais transeuntes seguem seus afazeres sem se afetar pelo espetáculo que se dá. Teatro e vida se encontram mas algumas vezes um dos dois acaba passando despercebido porque eles se misturaram muito organicamente, eles se fundem. A cidade se transforma em palco da representação e as suas ruas, prédios, casas e paredes servem como cenografia, e muitos dos elementos urbanos como postes, bueiros, telefones públicos, bancos e lixeiros se tornam adereços de cena. O público já não distingue mais o local cotidiano

\footnotetext{
${ }^{2}$ O Erro Grupo foi criado em março de 2001, em Florianópolis, e atualmente é composto por 5 integrantes sendo que, dentre eles, alguns foram alunos da UDESC. O espetáculo Desvio, assistido em 21 de março de 2007 ocorreu no centro de Florianópolis, e foi apresentado também em outras cidades brasileiras. Mais informações sobre o grupo podem ser encontradas no site www.errogrupo.com.br.
} 
do local ficcional pois eles se fundem e se tornam contínuos. Dessa forma mais do que apresentar um espetáculo teatral fora do edifício teatral o Erro Grupo consegue transformar o local cotidiano em extracotidiano sem, no entanto, fantasiar o espaço público e tirá-lo da vida pragmática, sem necessitar demarcar dentro da rua o espaço da ficção, como ocorre no teatro de rua tradicional, no qual muitas vezes podemos encontrar um objeto (corda, pedras, etc) que delimita o lugar da ação dos atores e os separa radicalmente do lugar da ação dos espectadores. No teatro pós-dramático essa separação é muito mais tênue e sutil do que no teatro de rua tradicional, pois tanto não se faz necessária essa separação clara entre atores e espectadores, quanto não se faz necessária a demarcação física desta separação.

Segundo Thies Lehmann (2007, p. 280 - 282) a escolha de um local para a encenação em manifestações de teatro pós-dramáticas pode ter origem em diferentes buscas e intenções. Pode-se querer reclamar um local enquanto espaço social, e assim ou utilizá-lo para realizar um espetáculo em sua própria configuração ou alterar essa configuração mas tomando o cuidado para não permitir que o caráter fundamental e específico do espaço seja alterado. Ou seja, utilizar o espetáculo para falar do local desejado dentro do próprio local. Pode-se querer utilizar o espaço para enfatizar a situação de exceção da manifestação teatral, ou seja, ressaltando-a enquanto acontecimento extracotidiano e acentuando a distância e a separação entre teatro e vida pragmática. Ou pode-se ainda, segundo Thies Lehman, desejar a ativação de espaços públicos, ou seja chamar a atenção para locais pelos quais as pessoas transitam todos os dias mas que já não percebem, pois estão esquecidos e muitas das vezes até abandonados. È essa última possibilidade a intenção mais clara e direta da utilização do espaço no espetáculo Desvio. A escolha por realizá-lo sempre em locais urbanos e centrais das cidades por onde é apresentado colabora para essa ativação, e através da encenação o espaço urbano deixa de ser apenas espaço de trânsito para retomar sua qualidade de lugar de encontro social. Outros elementos criados pelo espetáculo contribuem para isso, como muitas falas das personagens que destacam construções locais ou a fala final do espetáculo, dita pela narradora e que consiste na mesma pedindo ao público que não aplauda, mas sim que circule, lembrando a quem assistiu o espetáculo que a vida e a cidade continuam e são as mesmas, não acabam com o fim da peça. Intervenções do próprio espetáculo na arquitetura local, como os cartazes que são colados nas paredes das ruas pelas quais transita a encenação também colaboram para chamar a atenção para o espaço urbano esquecido. Da mesma forma, a interação 
inevitável de transeuntes que influenciam direta ou indiretamente no espetáculo intensifica essa ativação. Um bom e esclarecedor exemplo se deu no dia da apresentação relatada aqui. Neste dia havia uma criança de rua que de tanto assistir o espetáculo (que já ocorreu várias vezes em Florianópolis) e os ensaios (que também eram feitos nas ruas de Florianópolis) já havia decorado o texto. Ela passou, então, a encenação inteira do lado da personagem-narradora falando junto com ela suas falas e repetindo suas ações. Ao mesmo tempo que essa criança destacava a ação teatral do espetáculo, enfatizando que havia um texto decorado assim como ações definidas, ela o tornava ainda mais orgânico ao seu local, à rua, pois ela fazia parte do local e o local abrigava de forma convincente o espetáculo. A preponderância da intenção de reclamar atenção ao local social, no entanto, não impede que as duas outras intenções explicadas por Lehmann e citadas acima possam ser encontradas no espetáculo, pois todas elas cumprem uma função principal que é apresentar e ao mesmo tempo problematizar o espaço. Essa função, que é uma das buscas principais do teatro pós-dramático co-existe com a especificidade da recepção que Lehmann (Idem, p. 145) explica da seguinte forma: "o espectador do teatro pós-dramático não é impelido a uma imediata assimilação do instante, mas a um dilatório armazenamento das impressões sensíveis com 'atenção flutuante por igual' (..) tudo depende aqui de não compreender imediatamente". Neste sentido, Desvio não expõe claramente nem obviamente seus questionamentos acerca da sociedade, mas através de momentos de remetimento estimula a discussão da vida pragmática. Muitos signos híbridos criados pelo espetáculo colaboram para que não haja essa compreensão imediata. Em alguns dos outros trabalhos do Erro Grupo, como, por exemplo, o trabalho mais recente do grupo, intitulado Enfim um líder, que também se passa nas ruas, podemos encontrar esses mesmos recursos aplicados de diferentes formas, mas também contribuindo para reclamar e problematizar o espaço social.

Até o momento no presente artigo só tratamos de situações nas quais o espaço cênico deixa de ser o edifício teatral, no entanto, não se faz obrigatório no teatro pósdramático sair do edifício teatral para questionar seu local ou contexto:

As suas diversas expressões e formas de apresentação têm em comum que muitas vezes eles questionam também o próprio contexto, o lugar da apresentação, seja através de referências permanentes ao ambiente social, seja através de uma migração do espetáculo para o espaço urbano, ou também através da 
tentativa de usar o teatro inteiro (não só o palco) como espaço cênico e fazer os espectadores circularem. (Primavesi, 2004, p. 03)

Questionar o próprio edifício teatral e as relações entre atores e espectadores que ali há também pode ser uma forma de questionamento social contemporâneo. Diferentemente do que no drama, no qual, como explica Szondi (2001, p.31) "a relação espectadordrama conhece somente a separação e a identidade perfeitas, mas não a invasão do drama pelo espectador ou a interpolação do espectador pelo drama", no teatro pósdramático a relação espectador-drama se mescla e se funde a ponto de, talvez, uma completar a outra de forma a não ser possível separá-las. Questionar a sociedade midiática é também uma das buscas do teatro pós-dramático e a quebra e a fuga do espaço tradicional é elemento facilitador desse objetivo pois:

As condições básicas da cultura teatral atual já não são tão patentemente aquelas formuladas pela sociedade burguesa que, durante os séculos XVIII e XIX, podia criar para si um protegido espaço interno para discutir e elaborar suas estruturas sentimentais e valores morais. (Ibidem)

Faz-se necessário, então, buscar outras formas de relação. O espetáculo Desvio consegue atingir esse objetivo pois estimula a discussão política através da relação emocional dos espectadores com seu ambiente e ironiza as relações midiáticas durante a encenação, pois as cenas são claramente um remetimento as relações midiáticas. Cenas de violência que ocorrem no próprio local onde se passam as cenas verdadeiras, mas que para os espectadores parecem distantes pois são vistas sempre de forma midiatizada. Uma delas, talvez a mais clara, se dá quando a narradora, de costas para os acontecimentos narra como a vítima é espancada. Sua voz, no entanto, remete as narrações de telejornais, estruturados dramaturgicamente como um melodrama no qual as cenas tristes são maioria, mas o desenlace é composto de uma solução para todos os problemas, uma solução sempre emocional. È dessa forma que os espectadores se confrontam diretamente com o que parecia distante em sua própria cidade, e muitas vezes se chocam mais com essa simulação, porque a vêem ao vivo, do que com a realidade, porque a esta sempre vêem de forma virtual. Em um outro momento do 
espetáculo a vítima é novamente espancada. O local onde isso ocorre, no entanto, é escolhido com cuidado pois a cena se passa em um canto muito escuro de uma rua, uma região mais silenciosa e afastada em que, provavelmente, esta cena de espacamento já tenha ocorrido na realidade, na vida pragmática. Mais uma vez a escolha do espaço contribui para o questionamento social e a percepção do espaço público. A utilização de um local ao invés de qualquer outro está justamente no fato de o espaço ser estímulo de questionamento e ter possibilidade de remeter à vida diretamente.

Mesmo contendo muitos elementos dramáticos tradicionais, o trabalho Desvio nos apresenta vestígios de traços pós-dramáticos e nos ajuda a compreender e aceitar que, mesmo no Brasil, longe do contexto no qual o livro fundamental de Lehmann foi elaborado, pode-se perceber trabalhos que confluem para essa estética e mesclam elementos tradicionais com elementos contemporâneos de forma vanguardista. Um dos motivos que contribui para que isso seja possível é a existência das grandes mídias e dos avanços nas formas de comunicação que possibilitam trocar informações e conhecer rapidamente todo o mundo. Assim, ironicamente, ao mesmo tempo em que são causa, as novas mídias são também alvo de crítica do teatro pós-dramático. Este, no entanto, não esconde suas influências nem origens, mas não deixa de buscar autonomia. É preciso lembrar que, como já foi dito anteriormente, o espaço é apenas um dos elementos a ser analisado para se estudar e entender o teatro pós-dramático, e neste artigo demos apenas uma pincelada nas possibilidades e efeitos do espaço cênico. Não podemos afirmar que o espetáculo aqui citado pode ser classificado como pós-dramático nos termos de Lehmann, e nem essa era nossa intenção, mas sim demonstrar como esse termo e suas características já estão presentes e implícitos nas produções contemporâneas não apenas estrangeiras, mas também locais. Para uma análise completa se faz necessário pensar no contexto do espetáculo de forma muito mais complexa, pois, como afirma Silvia Fernandes (2006, p.09) “para Lehmann, o teatro pós-dramático não é apenas um novo tipo de escritura cênica. È um modo novo de utilização dos significantes no teatro”.

\section{REFERÊECIAS:}


1- BAUMGARTEL, Stephan. O surgimento de um teatro pós-dramático na Alemanha no fim do século XX - contextos históricos e estéticos. Scripta. n. 6. UNIANDRADE: Curitiba, 2008 (no prelo)

2- FERNANDES, Silvia. Subversão no palco. In: Humanidades, n 52, 2006. p. 7-18 3-FISCHER-LICHTE, Erika. Transformações. Trad. de Stephan Baumgärtel. Urdimento.n. 8. Florianópolis: UDESC, 2008. (no prelo).

4 - LEHMANN, Hans-Thies. Motivos para desejar uma arte da não compreensão. Trad. de Stephan Baumgärtel. Urdimento.n. 8. Florianópolis: UDESC, 2008. (no prelo).

5 - LEHMANN, Hans-Thies. Teatro pós-dramático. Trad. Pedro Süssekind. São Paulo: Cosac Naify, 2007.

6 - LEHMANN, Hans-Thies. Teatro Pós-dramático e Teatro Político. In: Sala preta, n 5, USP, 2005.

7 - MARINIS, Marco de. Algo que debe suceder: un happening. El nuevo teatro 1947 - 1970. Buenos Aires: Paidos, 1987. (p.63 - 88)

8- PRIMAVESI, Patrick. Orte und Strategien postdramatischer Theaterformen. In: ARNOLD, Heinz Ludwig (org.). Theater fürs 21. Jahrhundert. München: Edition Text + Kritik, 2004, p. 8 - 25. (tradução pessoal de Stephan Baumgärtel)

9- SZONDI, Peter. Teoria do drama moderno [1880 - 1950]. Trad. Luiz Sérgio Repa. São Paulo: Cosac \& Naify , 2001.

10 - VENDRAMINI, José Eduardo. O teatro de origem não-dramatúrgica. Sala Preta, 5, USP, 2005. 